\title{
INFLUÊNCIA DA LUZ E DA TEMPERATURA SOBRE A OXIDAÇÃO DO ÓLEO ESSENCIAL DE CAPIM-LIMÃO
} (Cymbopogon citratus (D.C.) STAPF)

\author{
Luiz Gustavo de L. Guimarães, Maria das Graças Cardoso*, Lidiany M. Zacaroni e Rafaela K. de Lima \\ Departamento de Química, Universidade Federal de Lavras, 37200-000 Lavras - MG, Brasil \\ Flávio A. Pimentel \\ Embrapa CNPAT, CP 3761, 60511-110 Fortaleza - CE, Brasil \\ Augusto R. de Morais \\ Departamento de Ciências Exatas, Universidade Federal de Lavras, 37200-000 Lavras - MG, Brasil
}

Recebido em 1/11/07; aceito em 29/2/08; publicado na web em 13/8/08

\begin{abstract}
INFLUENCE OF LIGHT AND TEMPERATURE ON THE OXIDATION OF THE ESSENTIAL OIL OF LEMONGRASS (Cymbopogon citratus (D.C.) STAPF). The identification of the chemical compounds of the essential oil was performed with a gas chromatograph coupled to a mass spectrometer. The oil was left in the presence and absence of light and submitted to different temperatures to evaluate its stability. The yields of the major compounds were evaluated every fifteen days. Citral and myrcene, the major compounds of the essential oil, were degraded over time in both the presence and absence of light, but temperature only influenced the degradation of myrcene.
\end{abstract}

Keywords: essential oil; Cymbopogon citratus; degradation.

\section{INTRODUÇÃO}

O mercado para os produtos naturais tem sido promissor e sua demanda, crescente; porém, a falta de qualidade da matéria-prima é um problema freqüente não só nos segmentos da produção agrícola, como também na estocagem do produto.

Cymbopogon citratus é conhecido popularmente no Brasil como capim-limão, capim-cidró, capim-cheiroso, capim-cidreira, capim-cidrão, citronela-de-java e erva-cidreira. Pertence à família das Gramíneas, subfamília Panicoideae. ${ }^{1}$ É uma planta aromática cultivada para produção comercial de óleo essencial, conhecido internacionalmente como óleo de Lemongrass.

Este óleo essencial possui forte odor de limão e é largamente empregado como aromatizante em perfumaria e cosmética, na preparação de colônias, sabonetes e desodorantes, porém, seu maior emprego tem sido na indústria farmacêutica, servindo de material de partida para síntese de importantes compostos, como iononas, metil-iononas e vitamina A. ${ }^{2}$ Sua composição química é relatada em diversos trabalhos, sendo o citral e o mirceno seus compostos majoritários, o citral é constituído pela mistura isomérica de geranial ((2E)-3,7-dimetilocta-2,6-dienal, citral A ou isômero E) e neral ((2Z)3,7-dimetilocta-2,6-dienal, citral B ou isômero Z). ${ }^{3}$ Outros aldeídos, como o citronelal, isovaleraldeído e decilaldeído, também podem ser encontrados, além de cetonas e álcoois, como geraniol, nerol, metil heptenol e farnesol. ${ }^{4-7}$

O citral, constituinte majoritário do óleo de $C$. citratus, é citado como sendo o responsável pelas atividades atribuídas ao seu óleo essencial, tais como germicidas, repelentes de insetos, aplicações na indústria farmacêutica, entre outras. Dessa maneira, há uma grande importância em avaliar o seu teor no óleo essencial, que nas plantações brasileiras está em torno de 75 a $86 \%$, valor bastante satisfatório para o mercado internacional. ${ }^{8}$

O mirceno, outro composto que pode ser encontrado em teores significantes no óleo essencial do capim-limão e também em outras

\footnotetext{
*e-mail: mcardoso@ufla.br
}

variedades de plantas, é um monoterpeno acíclico, de nome sistemático 7-metil-3-metileno-1,6-octadieno. Em vários estudos são demonstradas as atividades biológicas desse composto, capaz de interferir na biotransformação de drogas, como ciclofosfamidas, barbituratos, bromobenzeno quando presentes no organismo de mamíferos. ${ }^{9}$

Em geral, os óleos essenciais na presença de oxigênio, luz, calor, umidade e metais são muito instáveis, sofrendo inúmeras reações de degradação, o que dificulta a sua conservação, fazendo com que o seu processo de armazenamento seja fundamental para a manutenção de sua qualidade. ${ }^{10}$

Diante da importância comercial do óleo essencial de C. citratus, este trabalho teve como objetivo avaliar a sua estabilidade perante a luz e temperatura, visando encontrar as melhores condições de armazenamento que possam ser utilizadas para manter a qualidade do produto fornecido ao mercado.

\section{PARTE EXPERIMENTAL}

\section{Cultivo e colheita das plantas}

O material vegetal (folhas frescas de $C$. citratus) foi cultivado na Empresa de Produção de Sementes de Hortaliças "HORTIAGRO”, localizada no município de Ijaci - MG/Brasil. A coleta foi realizada no dia 25/5/2006 no período da manhã, em torno das $7 \mathrm{~h}$, com temperatura amena e ausência de chuva. Foram coletadas folhas jovens, cortadas a uma altura de $35 \mathrm{~cm}$ do solo.

\section{Extração do óleo essencial}

O processo de extração do óleo essencial foi realizado utilizandose um aparelho de Clevenger modificado adaptado a um balão de fundo redondo com capacidade de $4 \mathrm{~L} .{ }^{11}$ As folhas frescas de Cymbopogon citratus foram picadas, colocadas no balão e recobertas com água. $\mathrm{O}$ processo de extração foi realizado em um período de 2 h, mantendo-se a solução em ebulição. Posteriormente, coletou-se o hidrolato, que foi centrifugado em centrífuga de cruzeta horizontal 
a 965,36 x G por 5 min. O óleo foi retirado com o auxílio de uma pipeta de Pasteur, acondicionado em frasco de vidro e armazenado em freezer.

\section{Análise qualitativa e quantitativa do óleo essencial}

A análise qualitativa do óleo essencial foi realizada por cromatografia gasosa acoplada à espectrometria de massa (CG/EM). O cromatógrafo utilizado foi o modelo Shimadzu CG-17A equipado com detector seletivo de massa modelo QP 5000. O equipamento foi operado nas seguintes condições: coluna capilar de sílica fundida (30 $\mathrm{m} \times 0,25 \mathrm{~mm})$ com fase ligada DB5 $(0,25 \mu \mathrm{m}$ de espessura de filme); temperatura do injetor de $220^{\circ} \mathrm{C}$; programação da coluna com temperatura inicial de $40^{\circ} \mathrm{C}$, sendo acrescidos $3^{\circ} \mathrm{C}$ a cada minuto, até atingir $240{ }^{\circ} \mathrm{C}$; gás carreador hélio $\left(1 \mathrm{~mL} \mathrm{~min}^{-1}\right)$; pressão inicial na coluna: 100,2 KPa; taxa de split 1:10 e volume injetado de $1 \mu \mathrm{L}(1 \%$ de solução em diclorometano). Para o espectrômetro de massas (EM), foram utilizadas as seguintes condições: energia de impacto: $70 \mathrm{eV}$; velocidade de decomposição: 1000; intervalo de decomposição: 0,50; e fragmentos de 45 e $450 \mathrm{Da}$ decompostos. Foi injetada, nas mesmas condições da amostra, uma série de padrões de hidrocarbonetos $\left(\mathrm{C}_{9} \mathrm{H}_{20}\right.$ ....... $\mathrm{C}_{26} \mathrm{H}_{54}$ ). Os espectros obtidos foram comparados com o banco de dados da biblioteca Wiley 229 e o índice Kovat's calculado para cada constituinte foi comparado com o tabelado. ${ }^{12}$

A avaliação dos teores dos constituintes do óleo essencial foi feita utilizando-se um cromatógrafo gasoso Shimadzu GC 17A equipado com detector por ionização de chamas (FID), nas condições operacionais: coluna capilar DB5; programação da coluna: temperatura inicial de $40{ }^{\circ} \mathrm{C}$ até $240{ }^{\circ} \mathrm{C}$; temperatura do injetor: $220^{\circ} \mathrm{C}$; temperatura de detector: $240{ }^{\circ} \mathrm{C}$; gás carreador: nitrogênio $\left(2,2 \mathrm{~mL} \mathrm{~min}^{-1}\right)$; taxa de split 1:10; volume injetado: $1 \mu \mathrm{L}$ ( $1 \%$ de solução em diclorometano) e pressão na coluna de $115 \mathrm{KPa}$, sendo a quantificação de cada constituinte obtida por meio de normalização de áreas (\%).

\section{Análises da estabilidade dos constituintes majoritários}

Para verificação da estabilidade do óleo essencial avaliou-se a variação dos teores de citral e mirceno em relação ao tempo de exposição do óleo a diferentes temperaturas e ausência / presença de luz. Foram colocados $3 \mathrm{~mL}$ do óleo essencial em frascos de vidro transparente com capacidade para $10 \mathrm{~mL}$.

\section{Avaliação da estabilidade em relação à temperatura}

Para a avaliação da temperatura em relação ao tempo, os frascos foram envolvidos por papel alumínio para proteção contra a luz e devidamente vedados. Esses foram divididos em três lotes e acondicionados nos seguintes ambientes: geladeira na temperatura de $6,0 \pm 1,0^{\circ} \mathrm{C}$ (temperatura baixa); estufa com temperatura de $37,5 \pm$ $2,5^{\circ} \mathrm{C}$ (temperatura alta) e em temperatura ambiente com média de temperatura de $18^{\circ} \mathrm{C}$ (mínima de 10,7 e máxima de $28,3^{\circ} \mathrm{C}$ ).

Avaliação da estabilidade em relação à ausência/presença de luz

Para a avaliação da estabilidade perante a luz, os frascos foram mantidos em temperatura ambiente com média de $18^{\circ} \mathrm{C}$ (mínima de 10,7 e máxima de $28,3^{\circ} \mathrm{C}$ ) e divididos em dois tratamentos, um com os frascos envolvidos por papel-alumínio e outro com os frascos sem proteção, estando o óleo essencial exposto à luz. Os teores de citral e mirceno foram avaliados por cromatografia gasosa a cada 15 dias por um período de 120 dias, a partir da data de extração.

\section{Análises químicas}

As análises quantitativas de citral e mirceno foram efetuadas utilizando-se cromatógrafo gasoso Shimadzu GC 17A equipado com detector por ionização de chamas (FID), nas seguintes condições experimentais: coluna DB5; temperatura do injetor: $220^{\circ} \mathrm{C}$; temperatura do detector: $240^{\circ} \mathrm{C}$; programação da coluna com temperatura constante de $100^{\circ} \mathrm{C}$; gás carreador nitrogênio $(1 \mathrm{~mL} / \mathrm{min})$; taxa de split 1:20; volume injetado de $1 \mu \mathrm{L}$ (1,5\% de solução em diclorometano). Para a calibração externa, prepararam-se soluções com padrões de citral da Aldrich (95\% de pureza) e mirceno da Acrõs (90\% de pureza). A solução-padrão de citral foi preparada nas concentrações de 4, 6, 8, $10,12 \mathrm{mg} \mathrm{mL}^{-1}$, sendo constituída dos dois componentes, geranial e neral, utilizando diclorometano como solvente. Já a solução-padrão de mirceno foi preparada nas concentrações de 0,$5 ; 1,0 ; 1,5 ; 2,0$ e $2,5 \mathrm{mg} \mathrm{mL}^{-1}$ utilizando hexano como solvente. Por meio das curvas analíticas construídas com as soluções-padrão, determinaram-se os teores dos compostos analisados, transformando-se os valores de resposta registrados em teor dos componentes. A determinação do teor de citral foi dada pela soma das áreas do geranial e do neral. ${ }^{8}$

Foram realizadas análises por espectrometria no infravermelho com o óleo essencial fresco e para cada tratamento no fim de cada experimento com o intuito de verificar possíveis alterações nos grupos funcionais dos compostos presentes no óleo essencial. Os espectros foram obtidos em espectrômetro Excalibur Series Digilab FTS - 3000, utilizando-se a técnica de filme em janela de $\mathrm{KBr}$.

\section{Delineamento experimental e análise estatística}

O delineamento experimental utilizado foi inteiramente casualizado, com três repetições. Os tratamentos foram dispostos no esquema fatorial de 2 x 9 para avaliação quanto à luz, sendo constituído pelas combinações dos níveis de luz (presença e ausência) com os tempos de exposição $(0,15,30,45,60,75,90,105,120$ dias $)$ e $3 \times 9$, para avaliação quanto à temperatura, sendo construído pelas combinações das diferentes temperaturas (baixa, ambiente e alta) com os tempos de exposição $(0,15,30,45,60,75,90,105,120$ dias $)$. Para avaliar o comportamento dos constituintes em relação ao tempo de exposição dos experimentos fatoriais foi utilizada a análise de regressão. ${ }^{13}$

\section{RESULTADOS E DISCUSSÃO}

Os compostos encontrados no óleo essencial de C. citratus, seus teores e os índices de Kovat’s calculados estão representados na Tabela 1.

Tabela 1. Constituintes do óleo essencial de Cymbopogon citratus identificados por CG/EM e seus respectivos teores

\begin{tabular}{ccc}
\hline Constituintes & IK calculado & Teor $(\%)$ \\
\hline Mirceno & 991 & 23,77 \\
(Z)- $\beta$-ocimeno & 1040 & 0,50 \\
(E)- $\beta$-ocimeno & 1051 & 0,28 \\
Linalol & 1199 & 0,82 \\
Neral & 1244 & 31,89 \\
Geranial & 1273 & 37,42 \\
2-undecanona & 1292 & 0,27 \\
Outros & - & 5,87 \\
\hline Total & & 100 \\
\hline
\end{tabular}

Os componentes majoritários encontrados no óleo essencial de C. citratus, quantificados por normalização de áreas pela análise do cromatograma obtido por CG com detector FID, foram o neral $(31,89 \%)$ e geranial $(37,42 \%)$, seguidos pelo mirceno $(23,77 \%)$. Esses resultados estão de acordo com diversos autores, que afirmam a presença do citral como componente majoritário do óleo essencial 
de C. citratus. ${ }^{14,15}$

Pelos resultados obtidos na avaliação da estabilidade do óleo essencial de capim-limão, verificou-se que houve efeito significativo dos fatores luz e tempo e, também, da interação desses fatores sobre as porcentagens de citral e mirceno, que no início do experimento (tempo de 0 dia) eram de 73,70 e $17,38 \%$, respectivamente. Por meio dessa interação, observou-se a existência da variação do teor de citral e mirceno, que na ausência de luz ao fim do experimento (tempo de 120 dias) estavam presentes nas porcentagens de 50,03 e 8,62\%; já na presença de luz as porcentagens encontradas foram de 41,91 e $5,24 \%$, respectivamente, evidenciando uma redução no teor médio de mirceno e citral com o decorrer do tempo, variando em relação à presença/ausência da luz.

Nas Figuras 1 e 2 observam-se, pela análise de regressão, o decréscimo dos teores de citral e mirceno no óleo essencial em relação ao tempo e na presença /ausência de luz. Analisando os coeficientes angulares das equações para o decréscimo do teor de citral e mirceno, observou-se que os coeficientes angulares na presença de luz foram maiores ( 0,265 para o citral e 0,103 para o mirceno), o que evidencia uma maior taxa de degradação dos compostos na presença de luz.

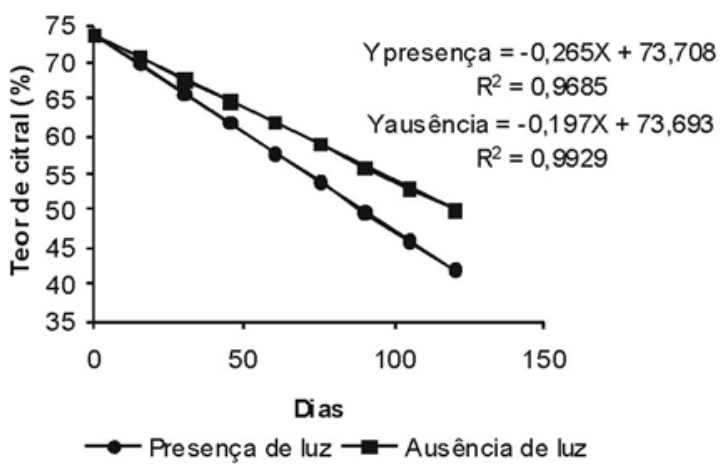

Figura 1. Decréscimo dos teores de citral no óleo essencial de Cymbopogon citratus em relação ao tempo e à presença/ausência de luz

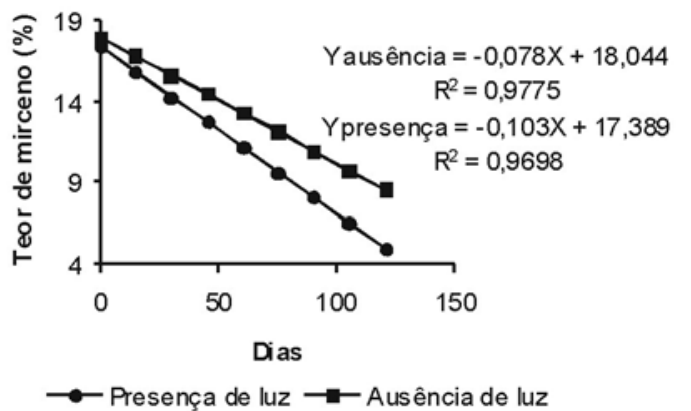

Figura 2. Decréscimo dos teores de mirceno no óleo essencial de Cymbopogon citratus em relação ao tempo e à presença/ausência de luz

Na avaliação da estabilidade dos constituintes majoritários do óleo essencial em relação à temperatura, observou-se uma variação significativa para as variáveis temperatura e tempo, para os dois compostos analisados; no entanto, a interação entre o tempo e a temperatura não foi significativa para o citral, que se encontrava na porcentagem inicial de $73,70 \%$, e que ao fim do experimento (tempo de 120 dias) eram de 50,28; 50,03 e 53,39\% para as temperaturas alta, ambiente e baixa, respectivamente. Não se observou variação significativa para a degradação do citral entre as temperaturas alta e baixa, ambiente e alta; no entanto, observou-se variação apenas entre as temperaturas baixa e ambiente. Para o mirceno, que estava presente inicialmente na concentração de $17,38 \%$, e que ao fim do experimento (tempo de 120 dias) se encontrava nas concentrações de 3,99; 8,62 e 10,99\% para as temperaturas alta, ambiente e baixa, respectivamente, observou-se variação significativa entre todas as temperaturas.

Avaliando a análise de regressão representada na Figura 3 para os teores de citral em relação ao tempo e à temperatura, observou-se uma proximidade nos valores dos coeficientes angulares das equações, representadas para cada temperatura, mostrando que o decréscimo no teor de citral foi similar para todas as temperaturas. A variação do teor de mirceno em relação às temperaturas pode ser observada na Figura 4, na qual se constata uma diferença nos coeficientes angulares, observando-se um maior valor para alta temperatura $(0,111)$, seguido da temperatura ambiente $(0,078)$ e da temperatura baixa $(0,066)$.

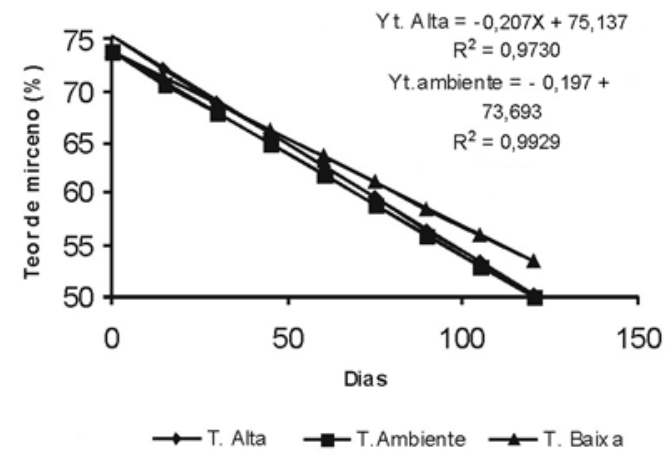

Figura 3. Decréscimo dos teores de citral no óleo essencial de Cymbopogon citratus em relação à temperatura

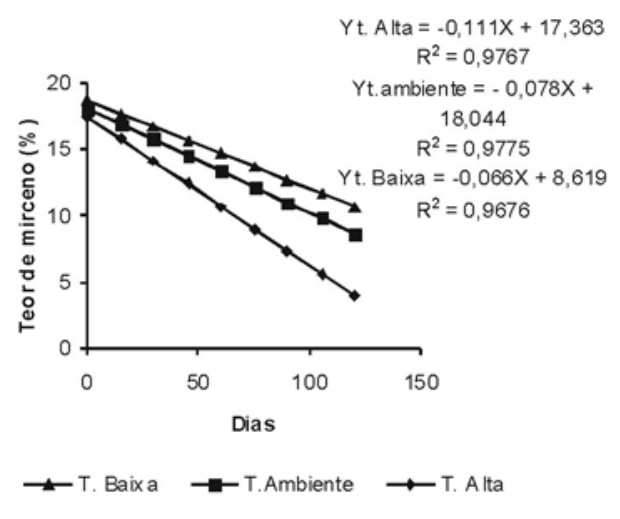

Figura 4. Decréscimo dos teores de mirceno no óleo essencial de Cymbopogon citratus em relação à temperatura

Considerando os resultados apresentados, pode-se inferir que os compostos mirceno e citral sofreram degradação em relação ao tempo. No entanto, essa degradação ocorreu tanto na ausência quanto na presença de luz, sendo em maior intensidade quando na presença de luz. Em relação à temperatura, observou-se influência dessa apenas sobre a degradação do mirceno, não se constatando variação para o citral.

O espectro no infravermelho, obtido da análise do óleo essencial fresco apresentou bandas características dos grupos funcionais que caracterizam os compostos majoritários do óleo essencial de capim-limão. Comparando o espectro do óleo essencial fresco com os espectros do óleo essencial submetido aos tratamentos, observaram-se modificações que evidenciam o aparecimento de grupos $\mathrm{OH}$, de ligações duplas 
carbono-oxigênio de ácidos carboxílicos e de peróxidos de acila. ${ }^{16}$

Os possíveis produtos de degradação não foram detectados nas análises cromatográficas finais, ao tempo de 120 dias, tanto para os tratamentos na presença de luz como para os tratamentos em relação à temperatura, uma vez que não houve aparecimento de novos picos nos respectivos cromatogramas.

Compostos orgânicos quando na presença de energia (que pode ser por aquecimento ou pela irradiação de luz) podem gerar radicais em decorrência da quebra homolítica de ligações químicas. Estes podem reagir com outras moléculas, gerando novos radicais, e com o oxigênio atmosférico, gerando peróxidos, hidroperóxidos, que são compostos instáveis capazes de serem quebrados em novos radicais ainda mais reativos. ${ }^{17}$

Na presença de radicais livres, o oxigênio pode atacar estruturas carbônicas insaturadas, especialmente na posição alílica. ${ }^{18}$ Os compostos citral e mirceno possuem em suas estruturas carbonos alílicos. Reações de origem radicalar ocorrem em compostos que possuem carbono alílico, por meio da perda de um hidrogênio desse carbono, pois o radical alílico é estabilizado por estruturas de ressonância desse com a ligação dupla presente no carbono vizinho. ${ }^{19}$ Assim, a degradação observada para os compostos estudados, mesmo na ausência de luz e em baixas temperaturas, pode ter ocorrido por processos radicalares, derivados da perda de um hidrogênio alílico.

O processo de autoxidação desses compostos pode ser semelhante ao apresentado para a autoxidação de ácidos graxos, que se inicia com a retirada de um hidrogênio alílico do composto, em condições favorecidas por luz e calor, gerando um radical alílico. Em seguida, esses radicais podem reagir com oxigênio do ar atmosférico e formar radicais peróxidos que, posteriormente, podem ser convertidos em hidroperóxidos, que vão atuar como propagadores da reação, que terá o seu fim com a combinação desses para a formação de produtos estáveis. ${ }^{20} \mathrm{O}$ mecanismo para a degradação do geranial via autoxidação está representado na Figura 5.

Compostos carbonílicos podem sofrer reações de fotólise quando expostos à luz, dando origem a vários produtos, inclusive radicais livres. ${ }^{18,21}$ Essa afirmação é coerente com o fato de o citral apresentar uma maior taxa de degradação quando na presença de luz. O grupo carbonílico de aldeídos é facilmente oxidado, mesmo à temperatura

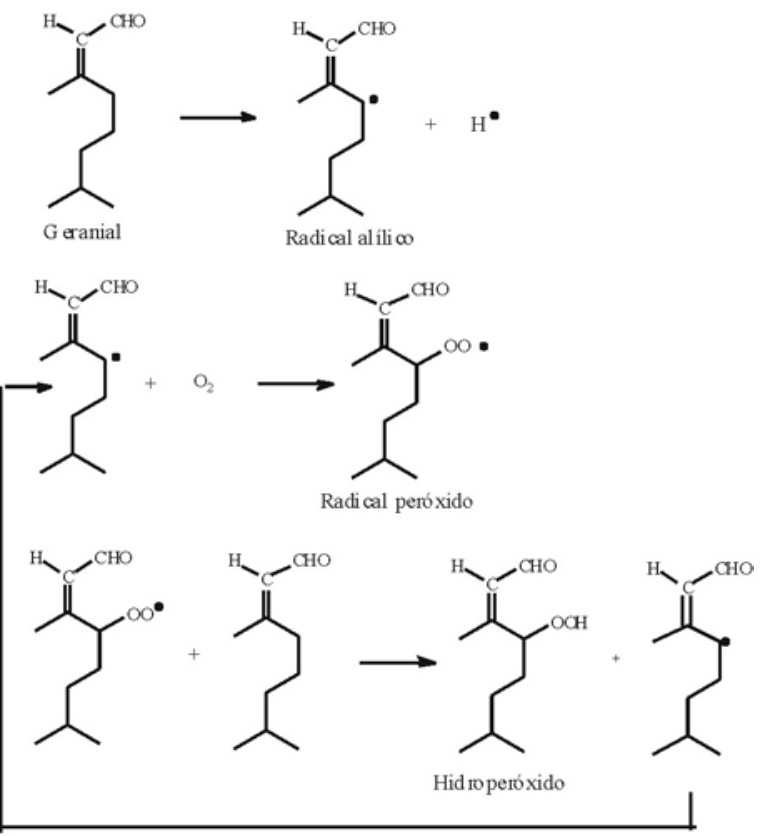

Figura 5. Mecanismo da degradação do geranial via autoxidação ambiente. Dessa forma, aldeídos podem ser oxidados pelo oxigênio do ar a ácidos carboxílicos e perácidos (Figura 6).22,23
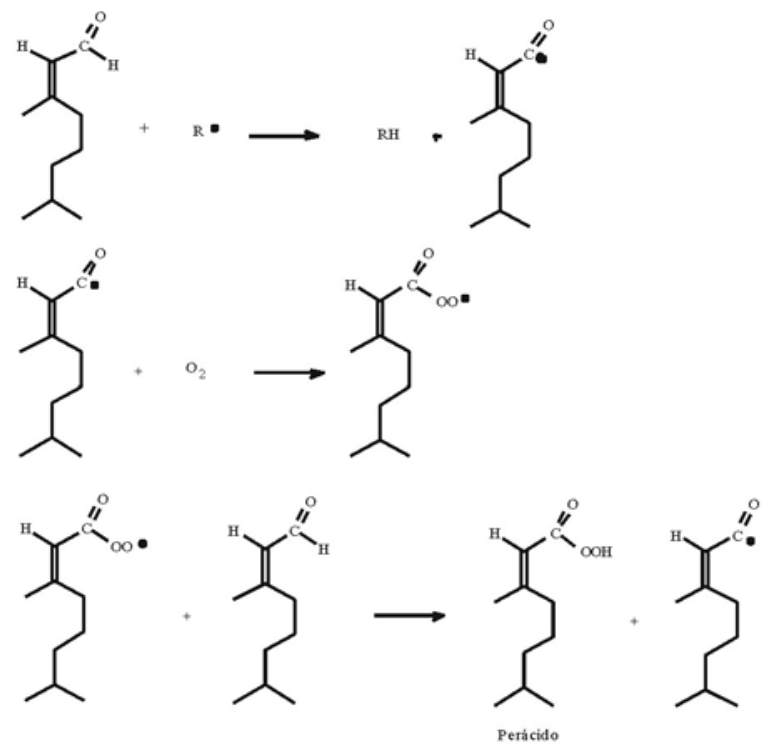

Figura 6. Oxidação do geranial a perácido

Compostos carbonílicos, quando na presença de luz, podem adicionar-se a alquenos, originando oxetanos. Esse processo pode ter ocorrido entre o citral e o mirceno. ${ }^{18}$

Já alquenos que possuem ligações duplas pouco substituídas podem se polimerizar na presença de radicais, pois esses se adicionam ao alqueno formando um novo radical alquila, reagindo esse com outras moléculas de alqueno, originando um radical polimérico; esta etapa é denominada de etapa de propagação. O término dessa etapa ocorre quando esses radicais reagem de maneira a formar compostos estáveis. ${ }^{19}$ Compostos insaturados também podem sofrer reações fotoquímicas de cicloadição, sendo essas reações observadas em muitos dienos conjugados, resultando na formação de diversos produtos. ${ }^{18}$

Essas reações provavelmente estão envolvidas no processo de decomposição do mirceno, já que este se polimeriza quando exposto ao ar e à luz. ${ }^{24}$

\section{CONCLUSÕES}

Os constituintes majoritários do óleo essencial de $C$. citratus, citral e mirceno sofreram degradação em relação ao tempo, tanto na presença quanto na ausência de luz. Em relação à temperatura, observou-se influência desta apenas sobre a degradação do mirceno. Apesar de ter ocorrido degradação, não se observou variação para o citral, mostrando que não sofre influência da temperatura no seu processo de degradação.

Tendo em vista que o citral além de ser o constituinte majoritário desse óleo essencial é também o composto de maior interesse pela indústria, conclui-se que este óleo essencial para fins de comercialização deve ser estocado ao abrigo da luz, não necessitando de temperaturas muito baixas para seu armazenamento.

\section{AGRADECIMENTOS}

À Empresa de Produção de Sementes de Hortaliças "HORTIAGRO” pela concessão do material vegetal, ao Laboratório de Análises e Sínteses de Agroquímicos do Departamento de Química da Universidade Federal de Viçosa (UFV) - Viçosa - MG pelas análises 
quantitativas do óleo essencial, ao Conselho Nacional de Desenvolvimento Científico e Tecnológico $(\mathrm{CNPq})$ pela bolsa de pesquisa e à Fundação de Amparo à Pesquisa de Minas Gerais (Fapemig) pelos recursos financeiros e concessão de bolsas.

\section{REFERÊNCIAS}

1. Abegaz, B.; Yohannes, P. G.; J. Nat. Prod. 1983, 46, 424.

2. Carvalho, C. M.; Costa, C. P. M.; Sousa, J. S.; Silva, R. H. D.; Oliveira, C. L.; Paixão, F. J. R.; Rev. Biol. Ciênc. Terr. 2005, 5, 1.

3. El Fattah, M. A.; El Zahwey, A.M.; Haridy, I. M.; El Deeb, S. A.; Menof. J. Agric. Res. 1992, 17, 1211.

4. Teske, M.; Trentini, A. M. M.; Herbarium Compêndio de Fitoterapia, $3^{\text {a }}$ ed., Herbarium: Curitiba, 1997.

5. Lewinsohn, E.; Dudai, N.; Tadmor, Y.; Katzir, I.; Ravid, U.; Putievsky, E.; Joel, D. M.; Annals of Botany 1998, 81, 35.

6. Costa, L. C. do B.; Corrêa, R. M.; Cardoso, J. C. W.; Pinto, J. E. B. P.; Bertolucci, S. K. V.; Ferri, P. H.; Hort. Brás. 2005, 23, 956

7. Pereira, A. A.; Dissertação de Mestrado, Universidade Federal de Lavras, Brasil, 2006.

8. Martins, P. M.; Melo, E. C.; Barbosa, L. C. A.; Santos, H. S.; Machado, M. C.; Acta Hort. 2002, 569, 155.

9. De-Oliveira, A. C. A. X.; Ribeiro-Pinto, L. F.; Paumgartten, F. J. R.; Toxicol. Lett. 1997, 92, 39.

10. Simões, C. M. O.; Schenkel, E. P.; Gosmann, G.; Mello, J. C. P.; Mentz, L. A.; Petrovick, P. R.; Farmacognosia: da planta ao medicamento, $5^{\mathrm{a}}$ ed., Ed. da UFSC: Porto Alegre, 2004.

11. Castro, D. P.; Cardoso, M. G.; Moraes. J. C.; Santos, N. M.; Baliza, D.
P.; Rev. Bras. Plant. Med. 2006, 8, 27.

12. Adams, R. P.; Identification of Essential Oils Components by Gas Chromatography/ Mass Spectroscopy. Carol Stream: Allured, 1995.

13. Pimentel-Gomes, F.; Curso de estatística experimental. Editora do Autor: Piracicaba, 2000.

14. Cimanga, K.; Kambu, K.; Tona, L.; Apers, S.; Bruyne, T.; Hermans, N.; Totté, J.; Pieters, L.; Vlietinck, A. J.; J. Ethnopharmacology 2002, 79, 213.

15. Kanko, C.; Sawaliho, B. E.; Kone, S.; Koukoua, G.; N'Guessan, T.; Compt. Rend. Chim. 2004, 7,1039.

16. Silverstein, R. M.; Webster, F. X.; Identificação espectrométrica de compostos orgânicos, $7^{\mathrm{a}}$ ed., Editora Livros Técnicos e Científicos: Rio de Janeiro, 2006.

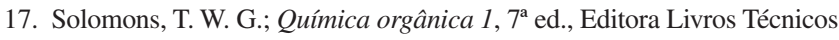
e Científicos: Rio de Janeiro, 2001.

18. Hendrickson, J. B.; Cram, D. J.; Hammond, G. S.; Organic chemistry, $3^{\text {rd }}$ ed., Mcgraw-Hill Book Company: New York, 1970.

19. Barbosa, L. C. A.; Introdução à Química Orgânica, Prentice Hall: São Paulo, 2004.

20. Ramalho, V. C.; Jorge, N.; Quim. Nova 2006, 29, 755.

21. Pryor, W. A.; Introduction to free radical chemistry, Ed. Prentice-Hall: New York, 1966.

22. Allinger, N. L.; Cava, M. P.; Jongh, D. C.; Johnson, C. R.; Lebel, N. A.; Stevens, C. L.; Química orgânica, $2^{\mathrm{a}}$ ed., Editora Livros Técnicos e Científicos: Rio de Janeiro: 1976.

23. Ege, S.; Organic chemistry, $3^{\mathrm{a}}$ ed., D. C. Heath and Company: Lexington, 1994.

24. Virmani, O. P.; Srivastava, R.; Datta, S. G.; World Crops 1979, 31, 120. 